\title{
BMJ Open Comparison of the aetiology of stillbirth over five decades in a single centre: a retrospective study
}

\author{
Karen Wou, ${ }^{1,2}$ Marie-Pier Ouellet, ${ }^{1,2}$ Moy-Fong Chen, ${ }^{1,2}$ Richard N Brown ${ }^{1,2}$
}

To cite: Wou K, Ouellet M-P, Chen M-F, et al. Comparison of the aetiology of stillbirth over five decades in a single centre: a retrospective study. BMJ Open 2014:4:e004635. doi:10.1136/bmjopen-2013004635

\section{- Prepublication history for this paper is available online. To view these files please visit the journal online (http://dx.doi.org/10.1136/ bmjopen-2013-004635).}

Received 31 December 2013 Revised 24 April 2014 Accepted 19 May 2014

\section{CrossMark}

${ }^{1}$ Department of Obstetrics and Gynecology, McGill University Health Centre, Montreal, Quebec, Canada ${ }^{2}$ Department of Pathology, McGill University Health Centre, Montreal, Quebec, Canada

\section{Correspondence to} Dr Richard N Brown; richard.brown@mcgill.ca

\section{ABSTRACT}

Objective: To compare the rates and aetiologies of stillbirth over the past 50 years.

Study design: We reviewed all autopsy reports for stillbirths occurring between 1989 and 2009 at the McGill University Health Centre to determine the pathological aetiology of stillbirths. We also reviewed maternal characteristics. We compared our results with a previous study published in 1992 on aetiologies of stillbirth from 1961 to 1988 at the same institution.

Results: From among the 79410 births between 1989 and 2009, 217 stillbirths were included in our study. The mean maternal age was $31.05( \pm 5.8)$ years. In $28.1 \%$ of cases, there was a history of subfertility. The mean gestational age at diagnosis was $32.69( \pm 5.58)$ weeks, with a birthweight of $1888( \pm 1084) \mathrm{g}$. The main causes of stillbirth were unknown (26.7\%), placental factors $(19.8 \%)$ and abruptio placentae $(12.9 \%)$. Other causes included haematogenous or ascending infection $(10.6 \%)$, fetal malformations $(8.3 \%)$, maternal hypertension $(3.2 \%)$, intrauterine growth restriction $(2.8 \%)$, diabetes $(1.8 \%)$ and intrapartum asphyxia $(1.4 \%)$. Other fetal causes were found in $12.4 \%$ of cases.

Conclusions: Owing to detailed pathological examination of most stillbirth cases over the past five decades at our tertiary obstetrical centre, we could study the trends in the aetiology of stillbirths in a cohort of more than 150000 births. In 50 years, the rate of stillbirth has decreased from 115 to 32 cases/ 10000 births from the 1960s to 2000s, which represents a reduction of $72 \%$. Stillbirth from unknown cause remains the most common contributor, with $40 \%$ of these cases occurring in late pregnancy.

\section{INTRODUCTION}

Stillbirth is defined as the death of a fetus $\geq 20$ th week of gestation or of weight $\geq 500$ g. ${ }^{1}$ Worldwide, stillbirth remains the most prevalent adverse outcome of pregnancy, estimated at 2.64 million in $2009^{2}$ and 1 in 160 pregnancies in the USA. ${ }^{3}$ The rates of stillbirth remain highest in developing countries but are likely underestimated due to poor access to obstetrical care and limited

\section{Strengths and limitations of this study}

- Despite the great numbers of papers recently published on stillbirths, we are one of the few institutions in North America who have been able to create a complete obstetrical and neonatal database with consistent pathological examination throughout the past five decades.

- However, there are a few limitations to our paper. Given the fact that our institution is a tertiary referral centre, our specific patient populations, with a greater proportion of high-risk pregnancies, may not exactly represent the general patient population in most community hospitals. Our results may be somewhat influenced by this tertiary centre bias.

- Also, the study of individual aetiology is somehow limited to a small number of cases per decade given the decreasing incidence of stillbirths with improved obstetrical care in the past decades.

- Another limitation is from the fact that 72 of our stillbirths could not be included in the analysis of the trend of aetiologies due to incomplete pathology examination or autopsy refusal. This represents almost a quarter of the cases of stillbirths during the study period. However, as protocols for stillbirth are being developed as standard obstetrical care, the use of autopsy examination should be more prevalent.

recordkeeping. ${ }^{4}$ Among the various recognised aetiologies of stillbirth, obstetric complications and placental abnormalities remain the most common in developed countries $^{5}$; however, a recent increase in the proportion of stillbirths caused by congenital malformations has been noted. ${ }^{6}$ The rate of unknown cause has remained the same over the past decades. ${ }^{7} 8$ Maternal obesity and advanced maternal age are now thought to contribute to an increasing proportion of stillbirths. ${ }^{9} 10$

This study aims to examine and evaluate the rates and aetiologies of stillbirths over the past 20 years at the McGill University Health Centre (MUHC). A previous study at 
this institution evaluated the period from 1961 to 1988 and demonstrated that the major cause of death was unknown. ${ }^{11}$ We will also compare our current data with the historical data previously derived.

\section{MATERIALS AND METHODS}

A retrospective cohort study was conducted at the MUHC with data from the Royal Victoria Hospital, a tertiary care centre and one of the main referral centres in the province. At this institution it has for many decades been the standard practice for all patients with a stillbirth to be offered a complete fetal autopsy and for all placentas to routinely be examined by a specialised team of technicians and perinatal pathologists. Parents have to consent to the autopsy and placenta analysis. A detailed external and internal examination of the fetus with microscopic examination of fetal and placental tissues is performed following a standard protocol. Our pathology database is regularly updated with all available cases.

All autopsy reports of stillbirths delivered between 1989 and 2009 were retrieved from our pathology database. For this study, the definition of stillbirth was defined as the birth of a fetus weighing $500 \mathrm{~g}$ or more with no signs of life. Pregnancy terminations were not included in this study.

We recognise that more than one cause may have contributed to any individual fetal death. To facilitate comparison with the earlier cohorts (1961-1988), with data collected similarly within our institution and published in 1992, the primary causes of fetal death were classified according to similar guidelines as described in table $1 .^{11}$ Complete pathological examination with clinical correlation at departmental meeting was used to determine the most likely primary cause. The cases that were not attributable to any of the principal categories were classified as 'others' with these in turn being subdivided as fetal or placental causes, depending on the final autopsy conclusions. All specific causes, comprising the 'others' category, are also listed in table 1 .

Medical charts of all pregnancy delivered at the MUHC, Montreal, Canada, are systematically reviewed by a specific team from our department. They retrieve all pertinent data from the charts to build the "Montreal Obstetrical and Neonatal Database' (MOND), which is a comprehensive computerised database of obstetrical and neonatal data for all deliveries at our centre. We used this database to retrieve relevant maternal information that could have affected pregnancy outcomes and be related to stillbirth. Accuracy of fetal characteristics including gestational age, birthweight and gender was also cross-referred between the pathology and the MOND database. Hypertension complicating pregnancy was defined as any hypertensive disorder diagnosed during pregnancy, whether chronic (prior to 20 weeks of gestation), pregnancy-induced hypertension or preeclampsia. Diabetes at the time of delivery included impaired glucose tolerance and all classes of diabetes from $\mathrm{A} 1$ to $\mathrm{T}$ (White classification). ${ }^{12}$ Subfertility was defined as at least 1 year of unprotected intercourse before the current pregnancy. Intrauterine growth restriction was defined as a birthweight less than the 5th centile for gestational age following the United States National Reference for Fetal Growth. ${ }^{13}$ Continuous variables were all described by mean values and SDs. Categorical variables were described by total numbers and percentages. Stillbirth rates were described per 10000 live births as in the previous paper. Rates were used to compare data between two decades, and percentages were used when comparing data within the same

Table 1 Classification of primary causes of fetal death

\begin{tabular}{|c|c|}
\hline Abruptio placentae & $\begin{array}{l}\text { Fetal death associated with antepartum bleeding and retroplacental blood clot, excluding placenta } \\
\text { previa }\end{array}$ \\
\hline Maternal diabetes & $\begin{array}{l}\text { Otherwise unexplained fetal death of appropriate for gestational age infants of diabetic or } \\
\text { glucose-intolerant mothers }\end{array}$ \\
\hline Infection & $\begin{array}{l}\text { Fetal death in which the fetus and/or the placenta show evidence of infection on pathological } \\
\text { examination, with or without clinical signs of maternal infection }\end{array}$ \\
\hline Intrapartum asphyxia & $\begin{array}{l}\text { Asphyxia related to labour and delivery, death without placental, cord, fetal or maternal cause. This } \\
\text { group is subdivided into deaths related to dystocia labour or malpresentation, and those otherwise } \\
\text { unexplained deaths occurring during apparently normal labour }\end{array}$ \\
\hline Fetal growth restriction & $\begin{array}{l}\text { Asphyxia or otherwise unexplained fetal death in a fetus } 25 \% \text { underweight ( } 2.4 \text { th centile) for } \\
\text { gestational age at time of death }\end{array}$ \\
\hline Isoimmunisation & Abnormal maternal antibodies and evidence of excessive fetal erythropoiesis \\
\hline Malformation & Potentially lethal anomalies take precedence over all other conditions \\
\hline Maternal hypertension & Otherwise unexplained fetal death of appropriate for gestational age infants in hypertensive mothers \\
\hline Unknown cause & $\begin{array}{l}\text { Death of an appropriate for gestational age fetus before labour with no evident fetal, maternal or } \\
\text { placental abnormality (with or without cord loops/knots) }\end{array}$ \\
\hline $\begin{array}{l}\text { Others-placental } \\
\text { causes }\end{array}$ & $\begin{array}{l}\text { Includes placental insufficiency, placental infarct, cord accident, cord thrombosis, cord prolapse, } \\
\text { vasculopathy }\end{array}$ \\
\hline Others-fetal causes & $\begin{array}{l}\text { Includes fetal blood loss, hydrops, twin-to-twin transfusion syndrome, fetomaternal haemorrhage, } \\
\text { fetal shock, fetal coagulopathy, decreased uteroplacental blood flow }\end{array}$ \\
\hline
\end{tabular}


decade. Descriptive analysis was conducted to present the results. Patient consent was obtained at the time of autopsy for diagnostic and research purposes.

\section{RESULTS}

From a cohort of 79410 births that delivered at the Royal Victoria Hospital between 1989 and 2009, 332 pathology reports for stillborn fetuses were retrieved. Of those, 43 were identified as terminations of pregnancy for medical or fetal indications and were excluded. Of the remaining 289 stillbirths, 70 did not undergo complete autopsy examination, primarily due to parental refusal. The overall autopsy rate was therefore $76 \%$. Two cases were rejected from the study because of possible interpretation bias. The first case was the death of a newborn, delivered at home and death was declared at the hospital soon after birth. The second case was excluded because placental pathological examination had not been performed. The final study population consisted of 217 stillbirths, although overall rates for this period were calculated from the total 289 stillbirths.

We first examined the maternal characteristics of these stillbirths (table 2). The mean maternal age was 31.05 \pm 5.86 years. The mean gravidity, parity and number of prior abortions were $2.48,0.8$ and 0.68 , respectively. In our study population, 23 patients had a twin pregnancy; 43 were smokers; 23 had hypertension and 12 had diabetes. In 65 cases, there was a history of subfertility. The mean gestational age at the stillbirth delivery was 32.69 \pm 5.58 weeks, with a birthweight of $1888 \pm 1084 \mathrm{~g}$. Of the 217 cases of stillbirth with full autopsy, 142 cases occurred in the decade from 1989 to 1999, and 75 cases occurred between 2000 and 2009, which is approximately a 50\% reduction in the number of stillbirths from one decade to the next (table 3). There were 52 stillbirth cases that

Table 2 Baseline maternal and fetal characteristics of the 217 stillbirth cases

\begin{tabular}{lcl}
\hline & $\begin{array}{l}\text { Total cases, } \\
\text { N (\%) }\end{array}$ & $\begin{array}{l}\text { Mean } \\
( \pm S D)\end{array}$ \\
\hline Maternal age & - & $31.05 \pm 5.86$ \\
Gravida & - & 2.48 \\
Parity & - & 0.80 \\
Aborta & - & 0.68 \\
Multiple gestation & $23(10.6)$ & - \\
Infertility & $65(30.0)$ & - \\
Smoking & $43(19.8)$ & - \\
Cannabis use & $9(4.2)$ & - \\
Previous caesarean & $21(9.7)$ & 0.12 \\
Caesarean birth & $23(10.6)$ & - \\
Gestational hypertension & $23(10.6)$ & - \\
Gestational diabetes & $12(5.5)$ & - \\
Female fetuses & $102(47.0)$ & - \\
Male fetuses & $115(53.0)$ & - \\
Gestational age (weeks) & - & $32.69 \pm 5.58$ \\
Birthweight (g) & - & $1888 \pm 1084$ \\
\hline
\end{tabular}

occurred before 28 weeks gestation; 72 cases between 28 and 34 weeks; 79 cases between 34 and 40 weeks and the remaining 14 cases after 40 weeks (table 3 ). Prematurity was proportionally similar (24\% before 28 weeks and $57 \%$ before 34 weeks) for both studied decades. The rate of pregnancies exceeding 40 weeks also remained unchanged from 1989-1999 to 2000-2009.

The most common cause of stillbirth was unknown $(\mathrm{n}=58$; table 4). Stillbirth from unknown cause has decreased from 45 cases between 1989 and 1999 to only 13 cases in the subsequent decade. This represents a near $50 \%$ reduction from the previous decade. We also evaluated the unexplained fetal deaths by gestational age (table 5). Nearly 40\% $(n=23)$ of these cases occurred in late pregnancy, between 34 and 40 weeks. There were only 7 cases in the postdates period, 12 cases in gestations <28 weeks and 16 cases in gestations between 28 and 34 weeks.

Abruptio placentae was the second most common cause, identified in 28 cases overall with a similar number of cases in both decades (15 and 13 cases, respectively). Although this appears to represent a slight increase in the cases of stillbirth secondary to abruptio placentae from $10.6 \%$ to $17.3 \%$, the rates remained similar (3.6 vs 3.5 cases/10 000 births, respectively) and the difference was not statistically significant $(p=0.116)$. Infection, including ascending and haematogenous infections, was the primary factor in 23 cases with a marked decrease of cases in 2000-2009 compared with 1989-1999 (1.1 vs 4.5 cases/10 000 births, respectively), a difference that reached significance $(p=0.05)$. Most infectious cases were from ascending chorioamnionitis with 14 cases occurring during 1989-1999 and only 3 cases during 2000-2009; the former decade including 3 cases of parvovirus B19 and 2 of unspecified villitis and the latter including 1 case of cytomegalovirus. Intrauterine growth restriction was identified as the primary aetiological factor in six stillbirths, none of which occurred in the latter decade. Given the small number of cases, this difference was not found to be statistically significant $(p=0.076)$.

Other placental or umbilical cord factors accounted for 43 cases, which represents an increase of 4.3-6.7 cases/10 000 births from 1989-1999 to 2000-2009. The majority of these were placental infarcts and cord accidents: 15 and 16 cases, respectively. The other cases

Table 3 Fetal deaths by gestational age from 1989 to 2009

\begin{tabular}{llll}
\hline Gestational & $\begin{array}{l}\text { Cases from } \\
\text { 1989 to 1999 }\end{array}$ & $\begin{array}{l}\text { Cases from } \\
\text { 2000 to 2009 } \\
\text { age (weeks) }\end{array}$ & $\begin{array}{l}\text { (\%) } \\
\text { Total cases } \\
\text { (\%) }\end{array}$ \\
\hline$<28$ & $34(23.9)$ & $18(24.0)$ & $52(24.0)$ \\
$28-34$ & $47(33.1)$ & $25(33.3)$ & $72(33.2)$ \\
$34^{+1}-40$ & $51(35.9)$ & $28(37.3)$ & $79(36.4)$ \\
$>40$ & $10(7.0)$ & $4(5.3)$ & $14(6.5)$ \\
Total & $142(65.4)$ & $75(34.6)$ & 217 \\
\hline
\end{tabular}


Table 4 Causes of death among stillbirths from 1989 to 2009

\begin{tabular}{lccc}
\hline Cause & Cases from $\mathbf{1 9 8 9}$ to $\mathbf{1 9 9 9}(\%)$ & Cases from $\mathbf{2 0 0 0}$ to $\mathbf{2 0 0 9}(\%)$ & Total cases (\%) \\
\hline Abruptio placentae & $15(10.6)$ & $13(17.3)$ & $28(12.9)$ \\
Maternal diabetes & $4(2.8)$ & 0 & $4(1.8)$ \\
Infection & $19(13.4)$ & $4(5.3)$ & $23(10.6)$ \\
$\quad$ Chorioamnionitis & $14(9.9)$ & $3(4.0)$ & \\
Cytomegalovirus & 0 & $1(1.3)$ & \\
Parvovirus B19 & $3(2.1)$ & 0 & $3(1.4)$ \\
Villitis & $2(1.4)$ & $1(1.3)$ & $6(2.8)$ \\
Intrapartum asphyxia & $2(1.4)$ & 0 & $18(8.3)$ \\
Intrauterine growth restriction & $6(4.2)$ & $6(8.0)$ & $7(3.2)$ \\
Malformation & $12(8.4)$ & $2(2.6)$ & $58(26.7)$ \\
Maternal hypertension & $5(3.5)$ & $13(17.3)$ & $43(19.8)$ \\
Unknown cause & $45(31.7)$ & $25(33.3)$ & $27(12.4)$ \\
Other-placental causes & $18(12.7)$ & $11(14.7)$ & 217 \\
Other-fetal causes & $16(11.7)$ & $75(34.6)$ & \\
Total & $142(65.4)$ & &
\end{tabular}

include placental insufficiency, cord prolapse, thrombosis and vasculopathy (table 6). Fetal malformations accounted for 18 cases while other fetal causes, such as fetal blood loss, twin-to-twin transfusion syndrome, hydrops, fetomaternal haemorrhage, fetal shock and coagulopathy, accounted for 27 cases. Although the overall rate for a fetal cause of stillbirth remained stable, there were no cases of hydrops in the latter decade 2000-2009. The remaining cases were attributable to maternal hypertensive disorders $(3.2 \%)$, diabetes $(1.8 \%)$ or intrapartum asphyxia (1.4\%); the frequencies of these were essentially unchanged across the two decades except for diabetes which was not a primary factor in any cases in the period 2000-2009 (table 4). Of note, no stillbirth consequent to isoimmunisation occurred during either of these two decades.

Our study results were compared with data from previous decades at this single institution. First of all, the total number of births per decade has increased significantly from 29101 births in the 1960s to 37537 births in the 2000s. There was a major overall improvement in the rates of stillbirths over the decades: 115/10 000 births in the $1960 \mathrm{~s}, 51 / 10000$ births in the 1980 s, $41 / 10000$ births in the 1990 s and $32 / 10000$ births in the 2000s. The above rates took into account the 72 stillbirth cases excluded from the study due to incomplete

Table 5 Unexplained fetal deaths by gestational age from 1989 to 2009

\begin{tabular}{llll}
\hline $\begin{array}{l}\text { Gestational } \\
\text { age (weeks) }\end{array}$ & $\begin{array}{l}\text { Cases from } \\
\mathbf{1 9 8 9} \text { to 1999 }\end{array}$ & $\begin{array}{l}\text { Cases from } \\
\mathbf{2 0 0 0} \text { to 2009 } \\
(\%)\end{array}$ & $\begin{array}{l}\text { Total } \\
\text { cases } \\
\text { (\%) }\end{array}$ \\
\hline$<28$ & $7(15.5)$ & $5(38.4)$ & $12(20.7)$ \\
$28-34$ & $12(26.7)$ & $4(30.8)$ & $16(27.6)$ \\
$34^{+1}-40$ & $19(42.2)$ & $4(30.8)$ & $23(39.6)$ \\
$>40$ & $7(15.5)$ & 0 & $7(12.1)$ \\
Total & 45 & 13 & 58 \\
\hline
\end{tabular}

pathological examination. This represents a $72 \%$ reduction in the overall rate of stillbirths from 1960-1969 to 2000-2009. Specific aetiologies of the 217 examined stillbirths were also compared with the previous study at the same institution. Unexplained stillbirths decreased from $38.1 / 10000$ births in the 1960 s to $20.6 / 10000$ in the 1970 s, $13.6 / 10000$ in the 1980 s to $7.3 / 10000$ in our current study. The number of stillbirths secondary to abruptio placentae was relatively stable in our study period: 3.6/10 000 births in the 1990s and 3.5/10 000 births in the 2000s. This was a significant reduction from previous decades: $11.6 / 10000$ in the 1960 s, $11.2 / 10000$ in the $1970 \mathrm{~s}$ and $7.2 / 10000$ in the $1980 \mathrm{~s}$. The rate of stillbirths due to infectious causes remained stable at $4.5 / 10000$ births over the decades until the most recent decade (2000s) where the rate dropped to 1.1/10 000 births. The rates of stillbirths from intrapartum asphyxia, malformations, diabetes and maternal hypertension have dramatically decreased over the decades (figure 1 ). There are no cases of Rhesus (Rh) isoimmunisation compared with $4.3 / 10000$ births in the 1960s. It would be difficult to compare the rates of stillbirths from other causes, as these were not classified as placental or fetal causes in the previous study. However, this category remained relatively stable over the decades as shown in figure 1. In our current study, there were no stillbirth cases of vasa previa or placenta previa. In summary, the most common aetiologies of stillbirths from the previous study by Fretts et al from 1961 to 1988 were unexplained cases, intrauterine growth restriction and intrapartum asphyxia. In comparison, over the subsequent two decades, unexplained stillbirth was still found to be the most common cause, followed by the broad categories of 'others' and abruptio placentae.

\section{DISCUSSION}

Detailed stillbirth examinations have been performed at our institution for several decades allowing the evolution of the aetiologies of stillbirth to be evaluated in a cohort 
Table 6 Fetal deaths due to miscellaneous causes

\begin{tabular}{lccc}
\hline & Cases from $\mathbf{1 9 8 9}$ to $\mathbf{1 9 9 9 ( \% )}$ & Cases from 2000 to 2009 (\%) & Total cases (\%) \\
\hline Placental causes & $18(41.9)$ & $25(58.1)$ & 43 \\
Placental insufficiency & 0 & $5(20.0)$ & $5(11.6)$ \\
Placental infarct & $7(38.9)$ & $8(32.0)$ & $15(34.9)$ \\
Cord accident & $9(50.0)$ & $7(28.0)$ & $16(37.2)$ \\
Cord prolapse & 0 & $1(4.0)$ & $1(2.3)$ \\
Cord thrombosis & 0 & $2(8.0)$ & $2(4.7)$ \\
Vasculopathy & $2(11.1)$ & $2(8.0)$ & $4(9.3)$ \\
Fetal causes & $16(59.2)$ & $11(40.7)$ & 27 \\
Fetal blood loss & $2(12.5)$ & $2(18.2)$ & $4(14.8)$ \\
Twin-to-twin transfusion & $4(25.0$ & $2(18.2)$ & $6(22.2)$ \\
Hydrops & $5(31.2)$ & 0 & $5(18.5)$ \\
Fetomaternal haemorrhage & $4(25.0)$ & $3(27.3)$ & $7(25.9)$ \\
Fetal shock & $1(6.3)$ & $1(9.1)$ & $2(7.4)$ \\
Fetal coagulopathy & 0 & $2(18.2)$ & $2(7.4)$ \\
Decreased uteroplacental blood flow & 0 & $1(9.1)$ & $1(3.7)$ \\
\hline
\end{tabular}

of over 150000 births from this single centre over a 50-year period.

Recently, Cousens et $a l^{2}$ estimated the global rate of stillbirths to be 2.64 million in 2009, compared with 3.03 million in 1995, a decline in the worldwide rate of $14.5 \%$, from 22.1 to $18.9 / 1000$ births between 1995 and 2009. The majority of stillbirths occur in low-income countries, and a WHO report in 2000 found that in developing countries, $60 \%$ of perinatal deaths are due to stillbirths compared with $40 \%$ in developed countries. ${ }^{14}$ Under-reporting is a major issue in developing countries given that half of stillbirths occur at home without appropriate prenatal care. ${ }^{15}$ Cousens et $a l^{2}$ emphasise the need for accurate data collection to gain a better understanding of the scope of the problem in order for global intervention programmes to be planned.
A review by Fretts ${ }^{16}$ evaluated strategies for stillbirth prevention in 113 articles. Interventions including $\mathrm{Rh}$ immune prophylaxis and intrapartum monitoring have contributed to a decrease in the rates of stillbirth. Recognition of risk factors such as obesity, poor socioeconomic status and advanced maternal age will identify patients in whom appropriate management and surveillance during their pregnancies should be implemented in order to improve outcomes and prevent stillbirths. ${ }^{17} 18$ Although previously unexplained stillbirths have been noted to increase with advancing gestational age, the risk reportedly doubling after 40 weeks' gestation ${ }^{19}$; our findings do not affirm this, with only $12 \%$ of all unexplained stillbirths occurring beyond 40 weeks. This is likely due to increasing inductions of labour for postdates pregnancy in our current practice, with few pregnancies going beyond 42 weeks. Improved outcomes for
Figure 1 Trends in the aetiology of stillbirth 1960-2009, McGill University Health Centre, Royal Victoria Hospital, Montreal, Canada.

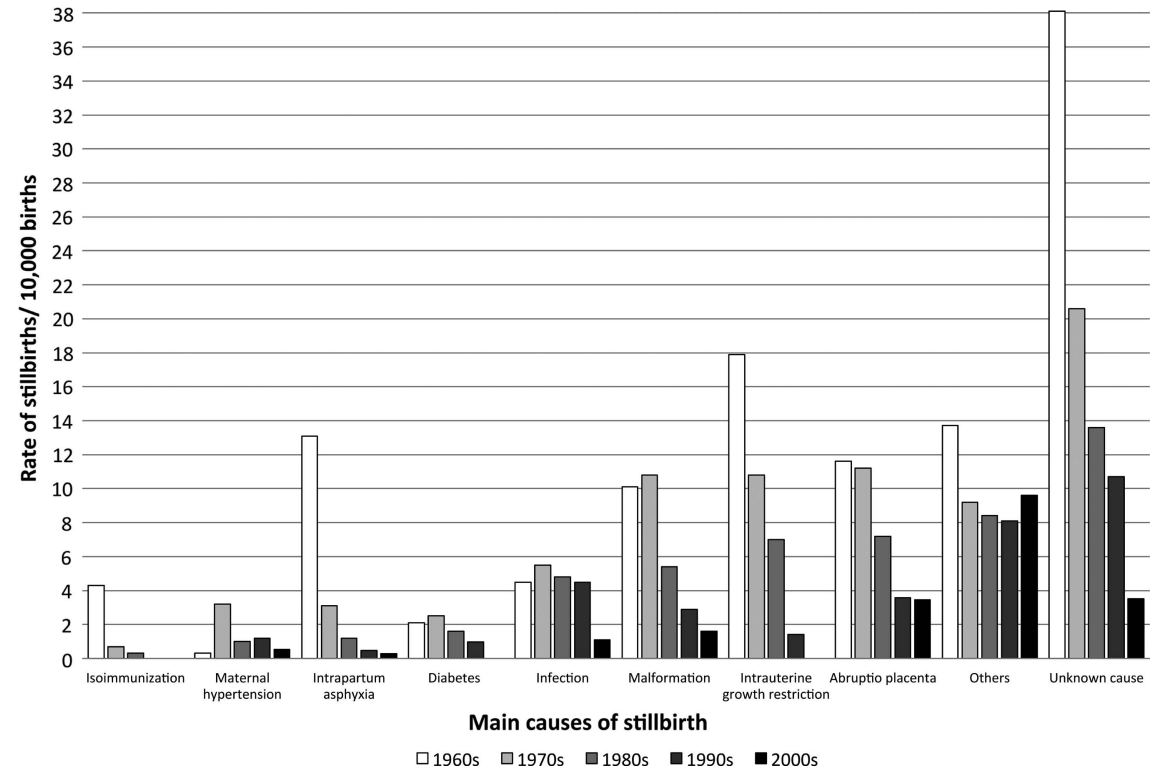


women with gestational diabetes are likely due to the intensive management and regular multidisciplinary follow-up provided at our institution. ${ }^{20}$

In a retrospective analysis of nearly 30000 term deliveries, unexplained stillbirths represented $51 \%$ of stillbirths $^{21}$ and in part this was attributable to incomplete assessments. In our data, the rate of unexplained stillbirths is much lower at $26.7 \%$. This is partially due to the routine approach of offering detailed fetal postmortem examination or limited examination when a full autopsy is declined; even when fetal autopsy is declined the placenta is evaluated. Nonetheless, asphyxia of unknown origin remains the most common contributor to stillbirth $(26.7 \%)$ with a significant proportion occurring in late pregnancy $(40 \%)$. Perhaps more in-depth fetal surveillance with complementary emphasis on placental function could help identify potential problems. Newer techniques including DNA analysis (eg, array comparative genomic hybridisation) and more comprehensive testing, for example, cytogenetic analysis of placental tissue evaluating mosaicism, may shed light on some of these cases. ${ }^{22}{ }^{23}$ Sebire et al suggest using noninvasive imaging techniques from multiple European studies between 1995 and 2010, for example, MRI for postmortem examination of stillborn fetuses. The $99 \%$ acceptance rate by parents compared favourably with the $60 \%$ for conventional autopsy. ${ }^{24}$

In conclusion, in our study, the total fetal death rate has decreased compared with previous studies at 3.2/ 1000 births (a $72 \%$ reduction in five decades from 1960-1969 to 2000-2009) with a complete autopsy available in $76 \%$ of cases. Stillbirth from unknown cause still remains the most frequent diagnosis for fetal demise. Abruptio placentae, sepsis and intrauterine growth restriction are the next most common aetiologies of stillbirth. These improvements reflect a more standardised obstetrical care, better fetal surveillance and timely delivery of high-risk pregnancies as well as steps towards a more comprehensive evaluation of stillbirth.

Contributors KW was the main author involved in the project. She worked on the acquisition, analysis and interpretation of data, and she was involved in the final manuscript preparation. M-PO performed the review of literature, acquisition and analysis of data, and preparation of the final manuscript. RNB was involved in the initial study design, data analysis, manuscript revision and approval for publication. He also supervised KW and M-PO at all stages of the project. M-FC was involved in the initial study design, data collection and interpretation, review and analysis of all the pathology reports included in the study. She was also involved in the manuscript revision and approval for publication and supervised each step of the project.

Funding This research received no specific grant from any funding agency in the public, commercial or not-for-profit sectors.

Competing interests None.

Ethics approval The McGill University Health Centre's institutional review board granted scientific review and ethical approval for this study.
Provenance and peer review Not commissioned; externally peer reviewed.

Data sharing statement No additional data are available.

Open Access This is an Open Access article distributed in accordance with the Creative Commons Attribution Non Commercial (CC BY-NC 3.0) license, which permits others to distribute, remix, adapt, build upon this work noncommercially, and license their derivative works on different terms, provided the original work is properly cited and the use is non-commercial. See: http:// creativecommons.org/licenses/by-nc/3.0/

\section{REFERENCES}

1. Joseph KS, Allen A, Kramer MS, et al. Changes in the registration of stillbirths $<500 \mathrm{~g}$ in Canada, 1985-95. Paediatr Perinat Epidemiol 1999;13:27-287.

2. Cousens $\mathrm{S}$, Blencowe $\mathrm{H}$, Stanton $\mathrm{C}$, et al. National, regional, and worldwide estimates of stillbirth rates in 2009 with trends since 1995 a systemic analysis. Lancet 2011;377:1319-30.

3. MacDorman MF, Kirmeyer S. Fetal and perinatal mortality, United States, 2005. Natl Vital Stat Rep 2009;57:1-19.

4. McClure EM, Nalubamba-Phiri M, Goldenberg RL. Stillbirth in developing countries. Int J Gynecol Obstet 2006;94:82-90.

5. The Stillbirth Collaborative Research Network Writing Group. Causes of death among stillbirths. JAMA 2011;306:2459-68.

6. Kalter H. Five-decade international trends in the relation of perinatal mortality and congenital malformations: stillbirths and neonatal death compared. Int J Epidemiol 1991;20:173-9.

7. Bell R, Parker L, MacPhail S, et al. Trends in the cause of late fetal deaths, 1982-2000. BJOG 2004;111:1400-7.

8. Bell R, Glinianaia SV, Rankin J, et al. The changing patterns of perinatal death, 1982-2000: a retrospective cohort study. Arch Dis Child Fetal Neonatal Ed 2004;89:F531-6.

9. Raymond EG, Cnattingius S, Kiely JL. Effects of maternal age, parity, and smoking on the risk of stillbirth. BJOG 1994;101:301-6.

10. Cnattingius S, Stephenson O. The epidemiology of stillbirth. Semin Perinatol 2002;26:25-30.

11. Fretts $\mathrm{RC}$, Boyd $\mathrm{ME}$, Usher $\mathrm{RH}$, et al. The changing pattern of fetal death, 1961-1988. Obstet Gynecol 1992;79:35-9.

12. White P. Pregnancy complicating diabetes. Am J Med 1949;7:609-16.

13. Alexander GR, Himes JH, Kaufman RB, et al. A United States national reference for fetal growth. Obstet Gynecol 1996;87:163-8.

14. World Health Organization. Neonatal and perinatal mortality for the year 2000: country, regional and global estimates. Geneva: World Health Organization, 2006.

15. McClure EM, Saleem S, Pasha O, et al. Stillbirth in developing countries: a review of causes, risk factors and prevention strategies. J Matern Fetal Neonatal Med 2009;22:183-90.

16. Fretts RC. Etiology and prevention of stillbirth. Am J Obstet Gynecol 2005;193:1923-35.

17. Smith G, Fretts R. Stillbirth. Lancet 2007;370:1715-25

18. Flenady V, Koopmans L, Middleton $\mathrm{P}$, et al. Major risk factors for stillbirth in high-income countries: a systematic review and meta-analysis. Lancet 2011;377:1331-40.

19. Yudkin PL, Wood L, Redman CW. Risk of unexplained stillbirth at different gestational ages. Lancet 1987;1:1192-4.

20. Syed M, Javed H, Yakoob MY, et al. Effect of screening and management of diabetes during pregnancy on stillbirths. BMC Public Health 2011;11(Suppl 3):S2.

21. Walsh CA, Vallerie AM, Baxi LV. Etiology of stillbirth at term: a 10-year cohort study. J Matern Fetal Neonatal Med 2008;21:494-501.

22. Goemaere N, Douben H, Van Opstal D, et al. The use of comparative genomic hybridization and fluorescent in situ hybridization in postmortem pathology investigation of congenital malformations. Pediatr Dev Pathol 2010;13:85-94.

23. Reddy UM, Page GP, Saade GR, et al. Karyotype versus microarray testing for genetic abnormalities after stillbirth. $N$ Engl J Med 2012;367:2185-93.

24. Sebire NJ, Taylor AM. Less invasive perinatal autopsies and the future of postmortem science. Ultrasound Obstet Gynecol 2012;39:609-11. 